\title{
Excess risk of mortality in very low birthweight triplets: a national, population based study
}

\author{
E S Shinwell, I Blickstein, A Lusky, B Reichman, in collaboration with the Israel \\ Neonatal Network
}

See end of article for authors' affiliations

.....................

Correspondence to: Dr Shinwell, Department of Neonatology, Kaplan Medical Center, Rehovot Israel; eric_s@clalit.org.il

Accepted 7 July 2002

\begin{abstract}
Background: Neonatal morbidity and mortality differ between singletons, twins, and triplets.
Objective: To evaluate whether plurality is associated with excess risk of neonatal morbidity and poor outcome (death, chronic lung disease, or adverse neurological findings) in very low birthweight (VLBW) infants from a national, population based cohort.

Methods: The Israel national VLBW infant database has prospectively collected extensive perinatal and neonatal data on all liveborn VLBW infants since 1995. The study sample ( $n=5594)$ consisted of all singletons $(n=3717)$ and all complete sets of twins $(n=1394)$ and triplets $(n=483)$ born during 1995-1999. To account for differences in case-mix, both univariate and multivariate comparisons that included confounding variables such as antenatal steroid treatment and mode of delivery were performed for each of the outcome variables.

Results: There was a small inverse correlation between gestational age (GA) and birth weight (BW) and the number of fetuses (singletons: GA 28.9 (2.6) weeks, BW 1096 (269) g; twins: GA 28.4 (2.3) weeks, BW 1062 (271) g; triplets: GA 28.5 (2.4) weeks, BW 1049 (259) g). Triplets were significantly more likely to have been conceived following fertility treatments, to have received antenatal steroids, and to be delivered by caesarean section. Respiratory distress syndrome was significantly more common in twins and triplets in spite of the increased exposure to antenatal steroids. Multivariate logistic regression analysis using all significant perinatal covariates showed that triplets were at increased risk of death (odds ratio (OR) 1.54, 95\% confidence interval (CI) 1.13 to 2.11 ), but not of adverse neurological outcome (OR 1.29, 95\% Cl 0.91 to 1.85 ) or chronic lung disease (OR $0.69,95 \% \mathrm{Cl} 0.46$ to 1.02 ).

Conclusion: Despite considerable differences in the incidence of confounding variables between the groups, VLBW triplets are at increased risk of death compared with twins and singletons. In addition, VLBW twins and triplets more often have respiratory distress syndrome but not chronic lung disease or adverse neurological findings.
\end{abstract}

$\mathrm{T}$ he last decade has seen an explosion in the use of assisted reproductive techniques which has resulted in a considerable increase in multiple births. ${ }^{2}$ As multiple pregnancies are more often delivered preterm, there has been a corresponding rise in the number of very low birthweight (birth weight $\leqslant 1500 \mathrm{~g}$; VLBW) infants. ${ }^{3}$

Studies have produced conflicting results on the effect of plurality on mortality and on the incidence of major morbidities, such as respiratory distress syndrome (RDS), intraventricular haemorrhage, chronic lung disease, and others. ${ }^{4}$ However, there is a paucity of large, population based studies comparing morbidity and mortality of singletons, twins, and high multiples. In particular, few studies have focused on the high risk VLBW infants. Since 1995, Israeli neonatologists and perinatologists, together with the Ministry of Health, have collaborated to establish and maintain a detailed database of all liveborn VLBW infants, which provides a unique opportunity to study this high risk population.

The aim of this study was to evaluate in a large population whether plurality is associated with excess risk of morbidity and mortality in VLBW infants.

\section{METHODS}

\section{Israel national VLBW infant database}

All infants of birth weight $1500 \mathrm{~g}$ or less who are born alive in any of the country's 28 neonatal units are included in the database. Data are prospectively collected on a structured form. These data include parental demographic information, maternal pregnancy history and antenatal care, details of the delivery, the infant's status at birth, diagnoses, procedures and complications during hospital stay, and outcome at discharge. All variables were defined by the scientific committee before data collection and have remained unaltered since. The definitions were based on those of the Vermont-Oxford Trials Network. ${ }^{5}$ Once collected by the local investigators, the data are sent to the database coordinator, checked for missing data and logic errors, corrected, completed, and then entered into a computerised database. Patient information is cross checked with the national birth registry, and data for any missing infant are requested from the birth hospital.

\section{Study sample}

For the purposes of this study, we selected all singletons and complete sets of twins or triplets with a birth weight of $1500 \mathrm{~g}$ or less and gestational age 24-34 weeks. Sets in which one member did not meet entry criteria were excluded. Infants born alive after induced terminations of pregnancy were excluded.

\section{Definition of outcome variables}

Death was defined as occurring before discharge from hospital. Chronic lung disease was defined as a clinical diagnosis of

Abbreviations: VLBW, very low birth weight; RDS, respiratory distress syndrome 
Table 1 Annual number (1995-1999) of all very low birthweight (VLBW) infants and singletons, twins, and high multiples in the Israel national VLBW infant database

\begin{tabular}{llllll}
\hline \multirow{2}{*}{ Year } & All VLBW infants & Singletons & All multiples & Twins & High multiples \\
\cline { 4 - 5 } & & $4045(57)$ & $3000(43)$ & $2131(30)$ & $869(12)$ \\
\hline Total & $7047^{*}$ & $726(61)$ & $469(39)$ & $324(27)$ & $145(12)$ \\
1995 & 1195 & $800(60)$ & $533(40)$ & $356(27)$ & $177(13)$ \\
1996 & 1333 & $825(56)$ & $639(44)$ & $464(32)$ & $175(12)$ \\
1997 & 1464 & $834(53)$ & $728(47)$ & $542(35)$ & $186(12)$ \\
1998 & 1562 & $860(58)$ & $631(42)$ & $445(30)$ & $186(13)$ \\
1999 & 1491 & & & & \\
\hline
\end{tabular}

Values in parentheses are percentages. $\mathrm{p}<0.01$ for trend of \% multiples.

*In two infants, plurality not recorded.

bronchopulmonary dysplasia and requirement for supplemental oxygen therapy at 28 days of life. Adverse neurological outcome was defined as one or more of the following: grade 3 or 4 periventricular-intraventricular haemorrhage, ${ }^{6}$ cystic periventricular leucomalacia, or posthaemorrhagic hydrocephalus. Small for gestational age was defined as more than 2 SDs below the mean based on the data of Usher and McLean ${ }^{7}$ for singleton births.

\section{Statistical analysis}

Differences between singletons, twins, and triplets with regard to maternal and infant characteristics were studied using the $\chi^{2}$ test for proportions and the General linear models for continuous variables. To assess the net effect of plurality on each of the three outcome variables, adjusted for other risk factors (covariates), a generalised logistic regression method was used by applying generalised estimating equations. This method accounts for interclass correlations in sets of multiple births. Results of the generalised logistic regression are presented as odds ratios (OR) with the appropriate $95 \%$ confidence intervals (CI). Statistical analyses were performed using the SAS statistical software (SAS Institute, Inc, Cary, North Carolina, USA).

\section{RESULTS}

\section{Rise in multiple births}

During the five years of the study period ( 1 January 1995 to 31 December 1999), there was a significant rise in the annual birth rate of VLBW infants (table 1). The rise was explained partly by a rise in the absolute number of total births and also by an increase in the proportion of multiples. Overall, 7047 infants were registered with the database, which comprise $99 \%$ of VLBW infant births in Israel. Of these, 5594 met study criteria, including 3717 (66\%) singletons, 1394 (25\%) twins, and $483(9 \%)$ triplets.

\section{Baseline maternal and infant characteristics}

The mothers of triplets were significantly more likely to have conceived with assisted reproductive techniques, to have begun antenatal care in the first trimester, to have received antenatal steroids, and to have delivered by caesarean section (all p < 0.001) (table 2). Maternal hypertension was significantly less common in twin and triplet pregnancies $(p<0.001)$. No difference was found between the groups in maternal age. A higher proportion of twins and triplets than singletons were of Jewish origin.

There was a slight, but significant, inverse relation between plurality and birth weight and gestational age. Triplets were

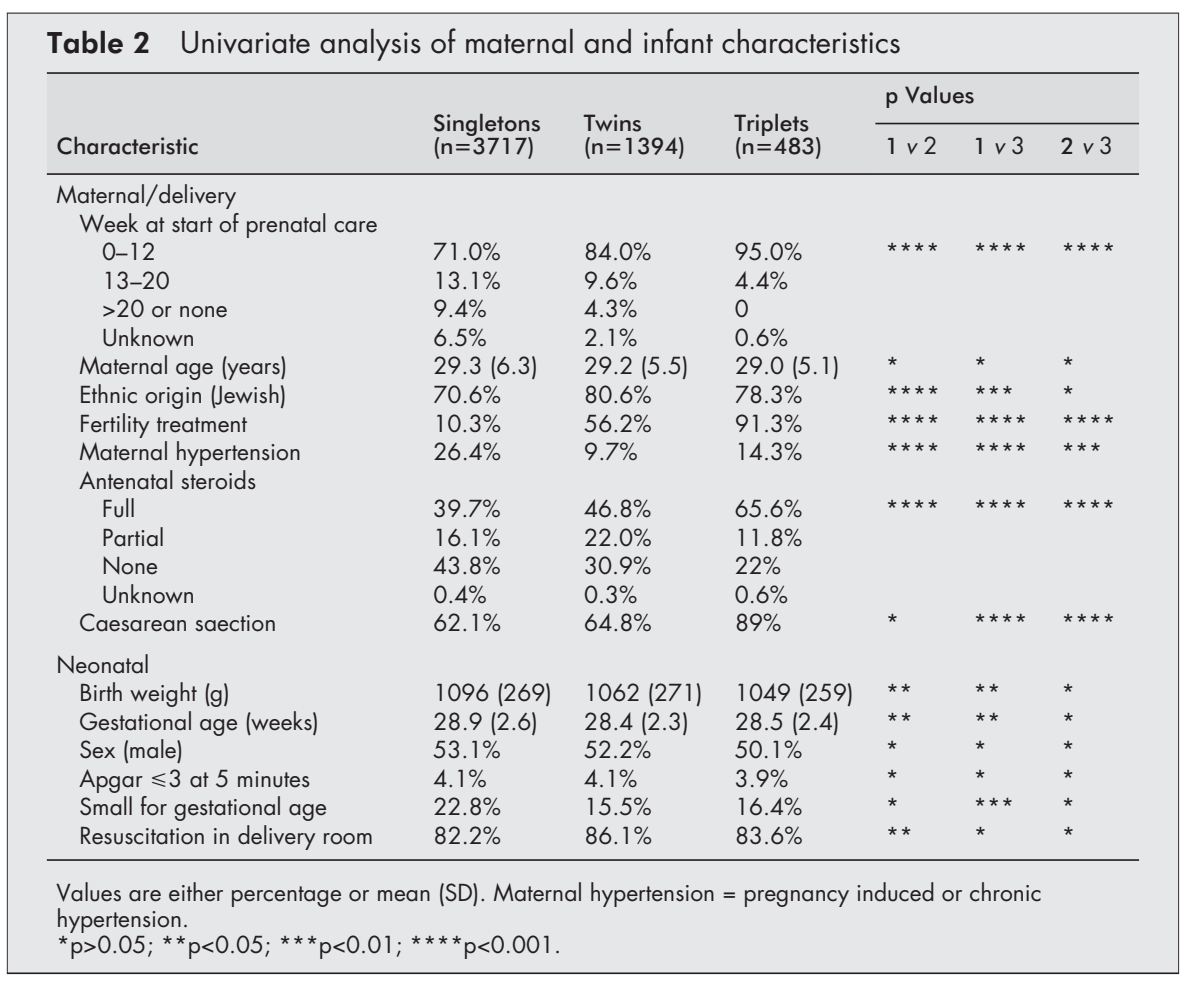


Table 3 Univariate analysis of poor outcomes and related morbidity

\begin{tabular}{|c|c|c|c|c|c|c|}
\hline & \multirow[b]{2}{*}{$\begin{array}{l}\text { Singletons } \\
\text { (\%) }\end{array}$} & \multirow[b]{2}{*}{$\begin{array}{l}\text { Twins } \\
(\%)\end{array}$} & \multirow{2}{*}{$\begin{array}{l}\text { Triplets } \\
(\%)\end{array}$} & \multicolumn{3}{|c|}{$\mathrm{p}$ Values } \\
\hline & & & & $1 \vee 2$ & $1 \vee 3$ & $2 \times 3$ \\
\hline Death & 20.1 & 21.7 & 22.4 & * & * & * \\
\hline Respiratory distress syndrome & 59.9 & 70.4 & 75.9 & $* * * *$ & ** & * \\
\hline Chronic lung disease & 23.2 & 25.3 & 19.4 & * & * & ** \\
\hline$\%$ CLD treated with steroids & 71.1 & 72.4 & 69.4 & * & * & * \\
\hline Adverse neurological findings (any) & 20.8 & 22.2 & 21.2 & * & * & * \\
\hline P-IVH grade $3 / 4$ & 11.7 & 12.9 & 11.2 & * & * & * \\
\hline PVL & 8.4 & 8.6 & 8.3 & * & * & * \\
\hline Hydrocephalus & 4.6 & 5.0 & 4.0 & * & * & * \\
\hline
\end{tabular}

on average $47 \mathrm{~g}$ lighter $(\mathrm{p}<0.01)$ and 0.4 weeks younger $(p<0.01)$ than singletons. Significantly more singletons were small for gestational age $(p<0.001)$. The infants were similar in sex distribution and Apgar scores, although singletons were slightly less likely to be resuscitated at birth $(\mathrm{p}<0.01)$.

\section{RDS}

RDS was diagnosed in $59.9 \%$ of singletons, $70.4 \%$ of twins, and $75.9 \%$ of triplet infants (table 3 ). In the multivariate analysis (table 4 ), both twins (OR 1.58, 95\% CI 1.32 to 1.89 ) and triplets (OR $2.51,95 \%$ CI 1.87 to 3.37 ) were associated with an increase in RDS. This difference is particularly striking in view of the increased exposure of triplets to antenatal steroids (table 2). Lack of antenatal steroid treatment was associated with an increased risk of RDS (OR 2.01, 95\% CI 1.7 to 2.35).

\section{Major outcome variables}

Univariate analysis showed no significant differences between the groups in the incidence of each of the outcome variables, except for a small difference between twins and triplets in the incidence of CLD (25.3\% $v 19.4 \%$; p < 0.05) (table 3$)$. No other significant differences were found between the groups in the incidence of major neonatal morbidity, such as sepsis, necrotising enterocolitis, patent ductus arteriosus, retinopathy of prematurity, or pulmonary air leak (data not shown).
In the multivariate analysis, triplets were at increased risk of mortality (OR $1.54,95 \%$ CI 1.13 to 2.11 ) but not of adverse neurological outcome (OR $1.29,95 \%$ CI 0.91 to 1.85 ) or chronic lung disease (OR 0.69, 95\% CI 0.46 to 1.02 ). Singletons and twins were at similar risk of poor outcomes (table 4).

\section{Covariates associated with poor outcome}

Vaginal delivery was associated with an increased risk of death (OR 1.42, 95\% CI 1.19 to 1.7 ) and adverse neurological outcome (OR 1.27, 95\% CI 1.05 to 1.53) (table 4). Lower gestational age, male sex, intrauterine growth retardation, need for resuscitation at birth, and RDS were all associated with significant increases in each of the poor outcomes.

\section{DISCUSSION}

This study shows that, despite earlier prenatal care, more antenatal steroids and delivery by caesarean section, VLBW triplets more often suffer from RDS and are at increased risk of death than twins or singletons.

Numerous previous studies have shown a clear inverse correlation between plurality and length of gestation. ${ }^{38}$ Alexander et $a l,{ }^{3}$ in a large, population based study, found the mean length of gestation to be 39 weeks in singletons, 35.8 weeks in twins, and 32.5 weeks in triplets. Accordingly, neonatal morbidity and mortality have been shown to be higher in

Table 4 Generalised logistic regression analyses for respiratory distress syndrome and poor outcomes (chronic lung disease, adverse neurological findings, and death)

\begin{tabular}{|c|c|c|c|c|}
\hline Risk factor & $\begin{array}{l}\text { RDS } \\
(n=5505)\end{array}$ & $\begin{array}{l}\text { CLD } \\
(n=4360)\end{array}$ & $\begin{array}{l}\text { Adverse neuro } \\
(\mathrm{n}=3955)\end{array}$ & $\begin{array}{l}\text { Death } \\
(n=5505)\end{array}$ \\
\hline \multicolumn{5}{|l|}{ Multiplicity } \\
\hline Singletons & 1.0 & 1.0 & 1.0 & 1.0 \\
\hline Twins & 1.58 (1.32 to 1.89$)$ & $0.96(0.76$ to 1.22$)$ & 1.09 (0.88 to 1.33$)$ & 1.12 (0.93 to 1.37 \\
\hline Triplets & 2.51 (1.87 to 3.37$)$ & $0.69(0.46$ to 1.02$)$ & $1.29(0.91$ to 1.85$)$ & 1.54 (1.13 to 2.11$)$ \\
\hline Maternal hypertension & 1.46 (1.22 to 1.75$)$ & $1.06(0.81$ to 1.40$)$ & 0.70 (0.54 to 0.91$)$ & 0.69 (0.53 to 0.91 \\
\hline Ethnic origin (non-Jews) & $1.05(0.91$ to 1.21$)$ & $0.97(0.83$ to 1.14$)$ & $0.96(0.82$ to 1.12$)$ & 1.03 (0.9 to 1.19$)$ \\
\hline \multicolumn{5}{|l|}{ Week at start of prenatal care } \\
\hline 0 to 12 & 1.0 & 1.0 & 1.0 & 1.0 \\
\hline 13 to 20 & $0.86(0.69$ to 1.07$)$ & $0.90(0.66$ to 1.22$)$ & 1.18 (0.9 to 1.56$)$ & 1.11 (0.85 to 1.45 \\
\hline$>20$ or none & 1.07 (0.82 to 1.40$)$ & 1.20 (0.79 to 1.82$)$ & 1.30 (0.94 to 1.78$)$ & 1.56 (1.16 to 2.1$)$ \\
\hline Unknown & 0.95 (0.68 to 1.33$)$ & $1.02(0.61$ to 1.69$)$ & 1.09 (0.68 to 1.73$)$ & 2.41 (1.66 to 3.5$)$ \\
\hline \multicolumn{5}{|l|}{ Antenatal steroid therapy } \\
\hline Full & 1.0 & 1.0 & 1.0 & 1.0 \\
\hline Partial & 1.53 (1.27 to 1.86 ) & $0.9(0.69$ to 1.18$)$ & 1.47 (1.15 to 1.88 ) & 1.04 (0.82 to 1.31$)$ \\
\hline None & 2.01 (1.72 to 2.35$)$ & $1.10(0.88$ to 1.38$)$ & 2.52 (2.06 to 3.07$)$ & $2.0(1.67$ to 2.4$)$ \\
\hline Gestational age (decrease of 1 week) & 1.58 (1.53 to 1.64$)$ & 2.19 (2.05 to 2.34$)$ & $1.33(1.27$ to 1.4$)$ & 1.66 (1.58 to 1.73 \\
\hline Male sex & 1.25 (1.09 to 1.42$)$ & 1.68 (1.40 to 2.02$)$ & 1.3 (1.1 to 1.54$)$ & 1.18 (1.0 to 1.38$)$ \\
\hline SGA & 0.81 (0.69 to 0.96$)$ & $3.03(2.20$ to 4.1$)$ & $1.3(1.01$ to 1.67$)$ & 4.31 (3.41 to 5.44 \\
\hline Vaginal delivery & $0.7(0.6$ to 0.82$)$ & $1.0(0.80$ to 1.25$)$ & $1.27(1.05$ to 1.53$)$ & 1.42 (1.19 to 1.7$)$ \\
\hline Resuscitation at birth & 3.29 (2.72 to 3.97$)$ & $1.98(1.31$ to 2.98$)$ & 2.04 (1.39 to 3.0$)$ & 1.55 (1.12 to 2.16 \\
\hline RDS & - & 5.03 (3.91 to 6.47$)$ & $2.0(1.6$ to 2.51$)$ & 1.82 (1.45 to 2.27 \\
\hline
\end{tabular}

Values are odds ratios (95\% confidence interval)

RDS, Respiratory distress syndrome; CLD, chronic lung disease; SGA, small for gestational age; neuro, neurological findings. 
twins and triplets, and this finding has mostly been attributed to the complications of prematurity. ${ }^{8}$

However, the hypothesis that these differences may be fully explained by differing gestational age has been questioned. Botting et al compared mortality in singleton and multiple pregnancies in England and Wales between 1978 and 1983 and found that differences in birthweight distribution did not wholly explain the differences in mortality. Synnes et al ${ }^{10}$ found higher adjusted mortality in twins than singletons of 24-28 weeks. The effect was considerable at 24 weeks and absent at 28 weeks. Buekens and Wilcox ${ }^{11}$ conducted a large study of birthweight specific mortality and found twins to be at higher risk in all weight groups. By comparison, some studies have not found twins to be at higher risk. Donovan et al ${ }^{12}$ compared outcomes of twins and singletons in the National Institute of Child Health and Disease Very Low Birth Weight network. No differences were found between the groups with respect to deaths, chronic lung disease, or grade 3/4 intraventricular haemorrhage. Wolf $\mathrm{et}^{l^{13}}$ found no differences in morbidity and mortality between VLBW twins and singletons.

A number of studies have compared outcome in triplets, twins, and singletons. ${ }^{14-22}$ However, these studies mostly included small samples, were uncontrolled for birth weight or gestational age, and did not focus on the high risk group of VLBW infants.

Some studies have adjusted for differences between the groups. Kaufman et al ${ }^{23}$ compared singletons, twins, and triplets of similar gestational age and found no significant differences in morbidity and mortality. However, this study included only 55 sets of triplets. Ericson $e^{2} \mathrm{al}^{24}$ conducted a registry based study of VLBW infants in Sweden in 1978-1983. Singletons and multiples were compared in $100 \mathrm{~g}$ groups by birth weight, and mortality was found to be higher in multiples. No correction was made for confounding variables. Luke ${ }^{25}$ studied birth statistics in the United States from 1983 to 1988. In a sample of 9523 infants, gestational age adjusted mortality was found to be higher in triplets. Neilsen et $a l^{26}$ reported a gestational age corrected comparison between singletons and multiples (mostly twins). Multiples suffered more often from RDS but there was no difference in mortality. Martin $\mathrm{et} \mathrm{l}^{27}$ studied US birth certificate data for 1971-1994 and found that triplets had a survival advantage over singletons at lower gestations. However, to the best of our knowledge, there are no large, population based studies comparing outcome in VLBW singletons, twins, and high multiples after correction for gestational age and relevant perinatal confounding variables.

A number of problems with our study need to be examined. Firstly, although the quality of the data was high and almost complete data were obtained on more than $98 \%$ of the infants born in the country during the study period, information on oxygen requirement at 36 weeks corrected gestational age was incomplete. This necessitated the use of an alternative and possibly less satisfactory definition of chronic lung disease, namely, requirement of oxygen at 28 days of life and a clinical diagnosis of bronchopulmonary dysplasia. However, oxygen requirement at 28 days correlates strongly with subsequent requirement at 36 and 42 weeks. $^{28}$ Secondly, data on intrauterine growth are limited by the fact that singleton growth charts were used for all infants and thus some of the multiples who were classified as small for gestational age may have been an appropriate size for gestational age on growth charts for multiples. Thus, although there were fewer small for gestational age infants among the multiples, this difference may in fact be even more pronounced than found here. Finally, there may be a selection bias inherent in the choice of VLBW infants only. It is possible that the differences seen here would not be found in larger, older infants.

Why was RDS more common in twins and triplets despite increased exposure to antenatal steroids? One possible explanation is that doctors dealing with triplets may choose to employ a prophylactic approach to surfactant administration shortly after delivery. This may result in an artificial overdiagnosis of RDS. However, this seems unlikely in view of the strong correlation between the diagnosis of RDS and each of the poor outcomes (table 4). Another possible explanation is diminished efficacy of antenatal steroid treatment in multiples. Available data have provided conflicting information, mostly because of small numbers of multiples in trials of steroid treatment. ${ }^{29} 30$

Why do triplets fare worse? Does the stressful situation of the delivery of three high risk infants result in a lower standard of care and thus poorer outcome? In this study, triplets did not have lower Apgar scores and did not require more resuscitative efforts. They did require more oxygen in the first 12 hours of life and at age 72 hours but this finding probably reflects the higher incidence of RDS. Subsequently, there was no significant difference in oxygen requirement between the groups (data not shown). Thus, if we can conclude that triplets receive similar care, then perhaps they have an intrinsic biological disadvantage compared with singletons or twins. This hypothesis can only be confirmed by large, population based studies of all singletons, twins, and triplets, in which data on all relevant variables are prospectively collected.

In summary, this is the first large, population based study to adjust for relevant perinatal confounding variables and then clearly show that VLBW triplets are at increased risk of RDS and mortality.

\section{ACKNOWLEDGEMENTS}

The Israel national very low birth weight database is supported by the Israel Center for Disease Control of the Ministry of Health.

The Israel Neonatal Network participating centres (in alphabetical order) are: Assaf Harofeh Medical Center, Rishon Le Zion; Barzilay Medical Center, Ashkelon; Bikur Holim Hospital, Jerusalem; Bnei Zion Medical Center, Haifa; Carmel Medical Center, Haifa; English (Scottish) Hospital, Nazareth; French Hospital, Nazareth; Hadassah University Hospital, Ein-Kerem, Jerusalem; Hadassah University Hospital, Har Hatzofim, Jerusalem; Haemek Medical Center, Afula; Hillel Yaffe Medical Center, Hadera; Italian Hospital, Nazareth; Kaplan Medical Center, Rehovot; Laniado Hospital, Netanya; Mayanei Hayeshua Hospital, Bnei Brak; Meir Medical Center, Kfar Saba; Misgav Ladach Hospital, Jerusalem; Nahariya Hospital, Nahariya; Poria Hospital, Tiberias; Rambam Medical Center, Haifa; Rivka Ziv Hospital, Tsfat; Schneider Children's Medical Center of Israel and Rabin Medical Center (Beilinson Campus), Petach Tikva; Shaarei Zedek Hospital, Jerusalem; Soroka Medical Center, Beersheva; Sourasky Medical Center, Tel Aviv; Wolfson Medical Center, Holon; Yoseftal Hospital, Eilat.

\section{Authors' affiliations}

E S Shinwell, I Blickstein, Kaplan Medical Center, Rehovot, Hebrew University, Jerusalem, Israel

A Lusky, B Reichman, Women and Children Health Research Unit, Gertner Institute, Sheba Medical Center, Tel Hashomer, Israel

\section{REFERENCES}

1 Martin JA, Park MM. Trends in twin and triplet births: 1980-1997. National Vital Statistics Reports 1999;47:24

2 Wilcox LS, Liely JL, Melvin CL, et al. Assisted reproductive technologies: estimates of their contribution to multiple births and newborn hospital days in the United States. Fertil Steril 1996;65:361-6.

3 Alexander GR, Kogen M, Martin J, et al. What are the fetal growth patterns of singletons, twins and triplets in the United States? Clin Obstet Gynecol 1998;41:115-25.

4 Warner BB, Kiely JL, Donovan EF. Multiple births and outcome. Clin Perinatol 2000;27:347-61.

5 Vermont-Oxford trials network database project. Manual of operations. Burlington, VT: Vermont-Oxford trials network, 1993:release 2.0 .

6 Papille LA, Burstein J, Burstein R, et al. Incidence and evolution of subependymal and intraventricular hemorrhage: a study of infants with birth weights less than 1500 grams. J Pediatr 1978:92;529-34.

7 Usher R, Mclean F. Intrauterine growth of live-born Caucasian infants at sea level: standards obtained from measurements in 7 dimensions of infants born between 25 and 44 weeks of gestation. J Pediatr 1969:74;901-10. 
8 Luke B, Keith L. The contribution of singletons, twins and triplets to low birth weight, infant mortality and handicap in the United States. J Reprod Med 1992;37:661-5

9 Botting BJ, Davies IM, Macfarlane AJ. Recent trends in the incidence of multiple births and associated mortality. Arch Dis Child 1987:62:941-50.

10 Synnes AR, Ling EWY, Whitfield MF, et al. Perinatal outcomes of a large cohort of extremely low gestational age infants (twenty-three to twenty-eight completed weeks of gestation). J Pediatr 1994;125:952-60.

11 Buekens P, Wilcox A. Why do small twins have a lower mortality rate than small singletons? Am J Obstet Gynecol 1993;168:937-41.

12 Donovan EF, Ehrenkrantz RA, Shankaran S, et al. Outcomes of very low birth weight twins cared for in the National Institute of Child Health and Human Development Neonatal Research Network's intensive care units. Am J Obstet Gynecol 1998;179:742-9.

13 Wolf EJ, Vintzileos AM, Rosenkrantz TS, et al. A comparison of pre-discharge survival and morbidity in singleton and twin very low birth weight infants. Obstet Gynecol 1992;80:436-9.

14 Ziadeh SM. The outcome of triplet versus twin pregnancies. Gynecol Obstet Invest 2000;50:96-9.

15 Seoud MA, Toner JP, Kruithoff C, et al. Outcome of twin, triplet and quadruplet in vitro fertilization pregnancies: the Norfolk experience. Fertil Steril 1992;57:825-34

16 Gonen R, Heyman E, Asztalos EV, et al. The outcome of triplet, quadruplet and quintuplet pregnancies managed in a perinatal unit: obstetric, neonatal and follow-up data. Am J Obstet Gynecol 1990; 162:454-9.

17 Sassoon DA, Castro LC, Davis JL, et al. Perinatal outcome in triplet versus twin gestations. Obstet Gynecol 1990;75:817-20.

18 Albrecht JL, Tomich PG. The maternal and neonatal outcome of triplet gestations. Am J Obstet Gynecol 1996;174:1551-6.

19 Collins JW, Merrick D, David RJ, et al. The Northwestern University Triplet Study. III. Neonatal outcome. Acta Genet Med Gemellol (Roma) $1988 \cdot 37 \cdot 77-80$
20 Angel JL, Kalter CS, Morales WJ, et al. Aggressive perinatal care for high-order multiple gestations: Does good perinatal outcome justify aggressive assisted reproductive techniques? Am J Obstet Gynecol 1999:181:253-9.

21 Weissman A, Talmon R, Jakobi P. The outcome of abdominally delivered triplets and twins: a matched case-control study. Eur J Obstet Gynecol Reprod Biol 1998;79:123-5

22 Fitzsimmons BP, Bebbington MW, Fluker MR. Perinatal and neonatal outcomes in multiple gestations: assisted reproduction versus spontaneous conception. Am J Obstet Gynecol 1998;179:1162-7.

23 Kaufman GE, Malone FD, Harvey-Wilkes KB, et al. Neonatal morbidity and mortality associated with triplet pregnancy. Obstet Gynecol 1998:91:342-8.

24 Ericson A, Gunnarskog J, Kallen B, et al. A registry study of very low birthweight liveborn infants in Sweden, 1973-1988. Acta Obstet Gynecol Scand 1992;71:104-11.

25 Luke B. Reducing fetal deaths in multiple births: optimal birthweights and gestational ages for infants of twin and triplet births. Acta Genet Med Gemellol (Roma) 1996;45:333-48

26 Nielsen H, Harvey-Wilkes K, MacKinnon B, et al. Neonatal outcome of very premature infants from multiple and singleton gestations. Am J Obstet Gynecol 1997;177:653-9.

27 Martin JA, MacDorman MF, Mathews TJ. Triplet births: trends and outcomes, 1971-94. Vital Health Stat 1997;55:1-20.

28 Egreteau L, Pauchard J-Y, Semama D, et al. Chronic oxygen dependency in infants born at less than 32 weeks gestation: Incidence and risk factors. Pediatrics $2001 ; 108: \mathrm{e} 26$

29 Royal College of Obstetricians and Gynecologists. Antenatal corticosteroids to prevent respiratory distress syndrome. London: Roya College of Obstetricians and Gynecologists, 2001.

30 Quist-Therson, Myhr TL, Ohlsson A. Antenatal steroids to preven respiratory distress syndrome: multiple gestation as an effect modifier. Acta Obstet Gynecol Scand 1999;78:388-92.

\section{This month in the Archives of Disease in Childhood}

The following papers appearing in the January 2003 issue of $A D C$ may be of interest to readers of Fetal and Neonatal.

Six month impact of false positives in an Australian infant hearing screening programme. Z Poulakis, M Barker, M Wake

Postnatal depression and infant growth and development in low income countries: a cohort study from Goa, India. V Patel, N DeSouza, M Rodrigues

Monitoring cardiac function in intensive care. SM Tibby, I A Murdoch 